\title{
Development of Key Performance Indicators for Rehabilitation, Murrin Murrin Nickel Operation
}

\author{
R. Loch Landloch Pty Ltd, Australia \\ T. Stevens Murrin Murrin Operations Pty Ltd, Australia \\ G. Wells $G$ and $G$ Environmental, Australia \\ R. Gerrard Rally Revegetation and Environmental Services, Australia
}

\section{BACKGROUND}

The Murrin Murrin Nickel Cobalt Project (Project) which is owned by subsidiaries of Minara Resources Limited and Glencore International AG and operated by Murrin Murrin Operations Pty Ltd (MMO), is located approximately $60 \mathrm{~km}$ east of Leonora in the North Eastern Goldfields of Western Australia. The Project includes open cut pits from which nickel laterite ore is mined using conventional open cut techniques and a processing plant which uses High Pressure Acid Leach (HPAL) technology to extract and recover the nickel and cobalt from the ore. Over the life of the mine, approximately 2500 ha of waste dumps are expected to be constructed. Progressive rehabilitation of disturbed areas was committed to by MMO when it obtained Project approval.

Based on current guidelines provided by the WA Department of Industry and Resources (DoIR), MMO is required to post an Environmental Performance Bond (Bond) on various areas disturbed by mining operations. Currently, for waste dumps, the rate is typically set at $\$ 10000$ per hectare (DME, 2003). If Bonds simply accumulated over the life of the MMO, waste dumps alone would represent a bond requirement of $\$ 25,000,000$. As Bonds (at differing rates) are also required for other areas of disturbance on the site, the potential total bond for MMO by completion of mining could be extremely large indeed. If no rehabilitation was done until completion of mining, MMO would not only have significant funds committed to performance bonds, but would then also need to provide a similar level of funding to carry out rehabilitation of the areas of disturbance. Funding that level of bonding plus rehabilitation requirements would create a considerable challenge for any company, illustrating that a commitment to progressive rehabilitation is both environmentally and economically responsible.

Current DoIR guidelines for Bonds allow for their progressive return on the basis of rehabilitation progress (Table 1), providing a strong economic incentive for the site to carry out progressive rehabilitation during the life of the mine and keep commitments to Bonds to as low a level as possible. However, that strategy faces two challenges. The first is to achieve stable and sustainable rehabilitation reliably and cost-effectively. The second is to establish an effective process for the assessment of rehabilitation success and the progressive return of Bonds on the basis of that assessment.

This paper describes the way in which MMO has dealt with both those challenges. 
Table 1 Suggested levels of Environmental Performance Bond reduction (DME 2003)

\begin{tabular}{|l|l|l|l|}
\hline Stage & Action & Completion Criteria Met & $\begin{array}{l}\text { Reduce bond } \\
\text { to \$/ha }\end{array}$ \\
\hline 1 & $\begin{array}{l}\text { Primary Earthworks } \\
- \text { Reshaping } \\
- \text { Drainage }\end{array}$ & $\begin{array}{l}\text { Structure stable. } \\
\text { Erosion controlled. } \\
\text { Water run-off managed effectively. }\end{array}$ & 5000 \\
\hline 2 & $\begin{array}{l}\text { Finishing Earthworks } \\
- \text { Topsoil spread } \\
- \text { Deep ripping }\end{array}$ & $\begin{array}{l}\text { Appropriate topsoil cover. } \\
\text { Adequate, contour ripping. } \\
\text { Demonstrated stability and erosion control. }\end{array}$ & 3000 \\
\hline 3 & $\begin{array}{l}\text { Revegetation } \\
- \text { Seeding } \\
- \text { Planting }\end{array}$ & $\begin{array}{l}\text { Vegetation established but not } \\
\text { demonstrated to be self-sustaining. } \\
\text { Weed control program commenced. } \\
\text { Grazing control commenced. }\end{array}$ & 2000 \\
\hline 4 & $\begin{array}{l}\text { Relinquishment } \\
\text { All actions complete }\end{array}$ & All criteria met. & 0 \\
\hline
\end{tabular}

\section{ACHIEVING STABLE, SUSTAINABLE REHABILITATION}

Prior to 2004, all dumps at MMO were rehabilitated in accordance with the Guidelines for Mining in Arid Areas (DME 1996). This involved re-contouring the waste dump batters to a gradient of $\leq 20^{\circ}$ with backward sloping berms every 3-12 meters of vertical height. Subsequent monitoring and assessment of these landforms found that a significant proportion of the dumps were subject to erosive failure, even though vegetation establishment was commonly good. Gullying was the common erosion mechanism in landforms constructed to the above guidelines using relatively fine and erosive materials. Gullying was associated with overtopping or failure of berms, uncontrolled discharges from the tops of waste dumps, and flow concentration by rip lines on uneven slopes (Figure 1).

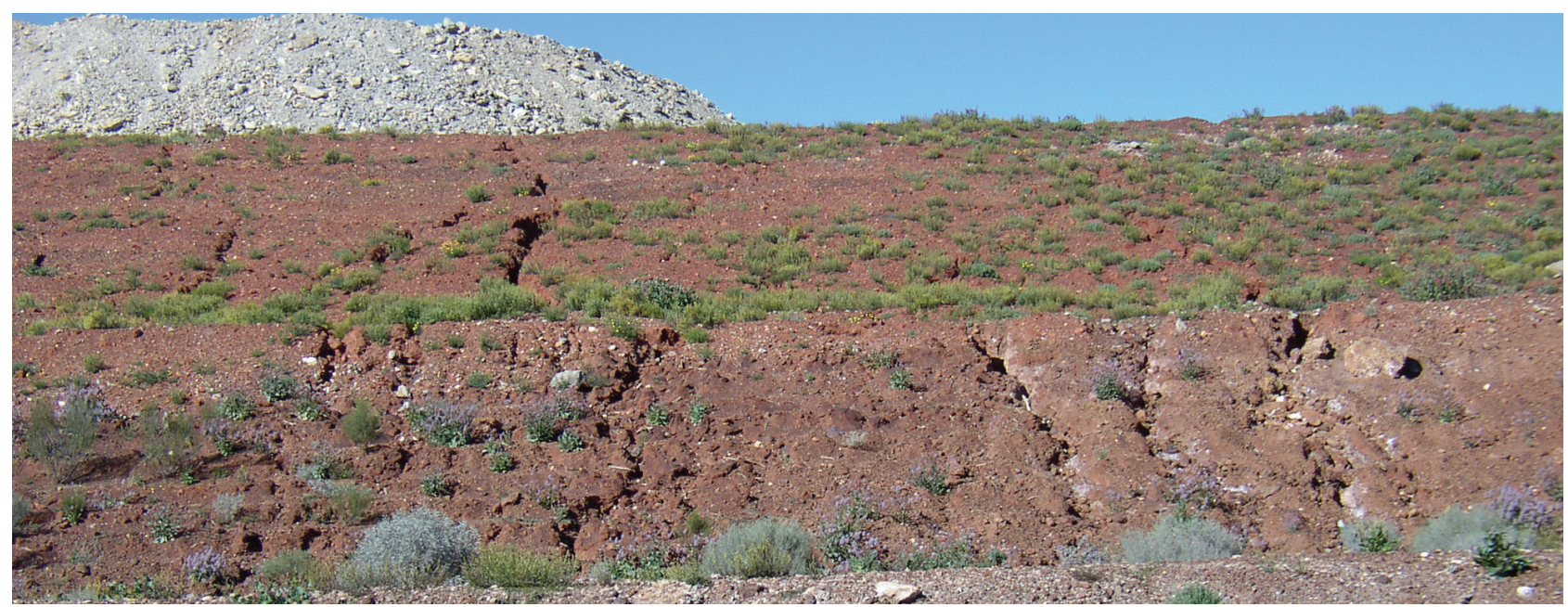

Figure 1 Typical pattern of rill and gully erosion on initial landforms at MMO

To address these issues, a different approach to landform design has been adopted. The planning process commences with assessment of the erosion potential of the materials being used to construct the landform. This information enables erosion modelling to be used to develop designs for outer batter slopes that are both site and material-specific. Known failure mechanisms such as berms are generally eliminated, and areas of the batters with greatest erosion risk are identified for additional treatments to control erosion; these include 
placement of laterite rock and tree debris. The aim of the design process is not to eliminate erosion, but rather to produce a landform on which erosion will be at a low and sustainable level. Because of the relatively high erodibility of the materials used in landform construction at MMO and the lack of rocky materials, the batter slopes constructed have typically used concave profiles to reduce erosion to acceptable levels. Figure 2 shows (for a relatively stable situation) the modelled differences between linear and concave slopes, with the concave profile keeping erosion at all points on the slope to relatively low rates. In contrast, the linear slope shows relatively high rates of erosion developing as slope length increases. Figure 2 also shows that uncontrolled run-on from the top of the landform can be a major cause of high erosion rates.

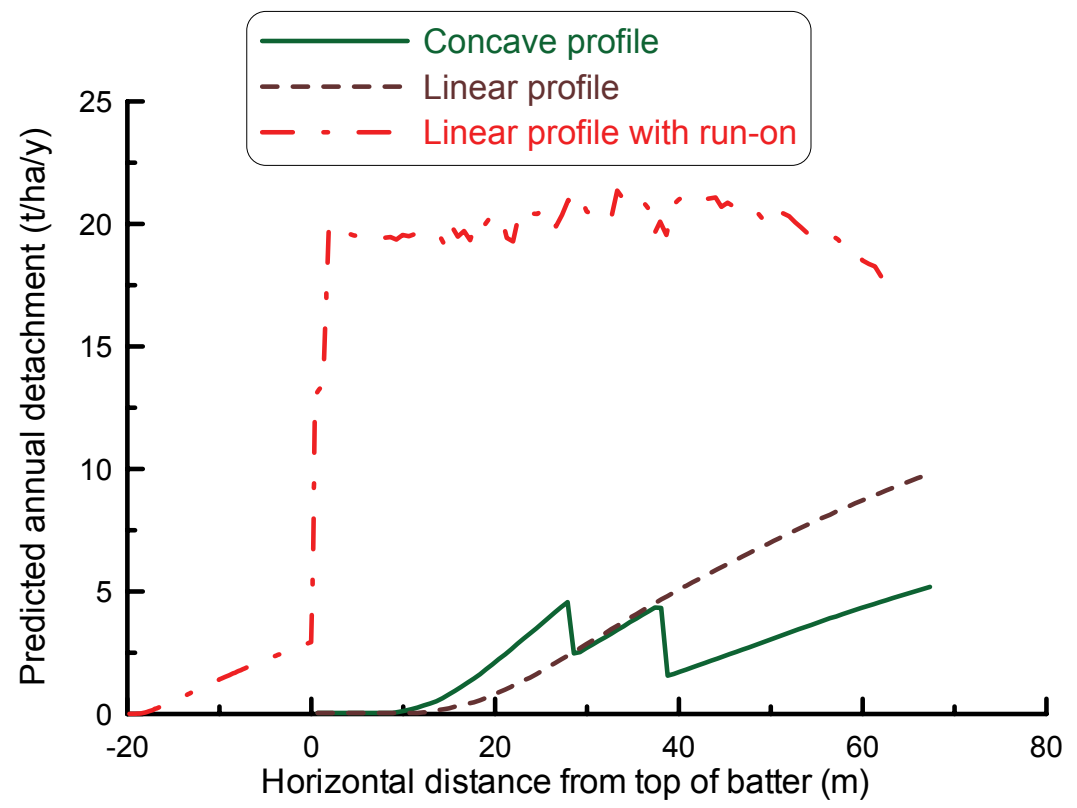

Figure 2 Output from WEPP runoff/erosion model simulations of erosion on a range of outer batter options using input parameters for MMO materials, including the situation of uncontrolled run-on from the top of the landform

Also of importance during the design phase is assessment of soil and waste properties to identify limitations to soil fertility and stability.

To date, nine landforms or landform batter slopes have been constructed using this approach. Where constructed to specification, the landforms have shown stability through rainfall events up to 1:10 year ARI daily rain, and vegetation establishment has responded well to recent rain.

\section{ASSESSING REHABILITATION SUCCESS - THE KPI APPROACH}

Rehabilitation incurs considerable cost. For that expenditure to be justified, any mining company requires some certainty that the expenditure will be recouped (to at least some degree) via a reduction in Bonds. This not only places some responsibility on site staff to achieve reliable outcomes in its rehabilitation process, but also creates a need for certainty in the assessment of rehabilitation success and return of Bonds.

For that reason, in 2004, MMO commenced the development of Key Performance Indicators (KPIs) of rehabilitation success. This approach was adopted to create certainty for MMO in its rehabilitation responsibilities and in the potential for bond return and/or reduction. The KPI process provides quantitative, objective and repeatable evaluation of rehabilitation, with the ability to tailor rehabilitation activities to the specific needs and risks of individual sites.

Once KPIs were developed, these were discussed with regulatory authorities, with the potential for amendment or alteration as necessary, to reach final agreement on a set of KPIs that were acceptable both to regulatory authorities and MMO. Importantly, this process ensures long-term continuity in the way in which rehabilitation success is monitored and recognized, irrespective of changes in staff in any of the organizations involved. 


\subsection{Overview of KPI Development}

Consideration of good rehabilitation practice (as understood by all involved) identified five Key Components. These are as follows:

- Planning.

- Construction.

- Initial Performance.

- Monitored Performance.

- Sustainability.

Although these steps are generally implemented by all mines, it is rare for some of these components to be explicitly recognized. For MMO, each of the five Key Components is explicitly considered, with a range of specific KPIs being developed for each Key Component.

Planning is an essential (though often neglected) component of successful landform rehabilitation, and the KPIs associated with Planning include specific site, vegetation, and material characterization activities that provide essential information for landform design, construction, fertiliser and amendment applications, seeding, and subsequent monitoring.

For example, identifying the vegetation rehabilitation objectives and development of completion criteria is a component of the Planning stage. This process involves establishing permanent monitoring points in natural reference communities and undertaking vegetation surveys to provide a range of values for a variety of quantitative measures in natural communities against which rehabilitated communities may be compared. Specific outcomes include photographs and GPS co-ordinates of monitoring transects, and a range of quantitative measures of plant density, diversity, and cover for natural communities from which the completion criteria were adopted.

It is rare for emphasis to be put on the quality or accuracy of construction of rehabilitated landforms. Effectively, this Key Component and associated KPIs creates a requirement for quality control. Across Australia, examples of landform failure due to poor construction are common, and Construction was included as a Key Component not only to ensure that construction is done to specification, but to also build recognition that quality of construction is important.

The "end goal" of KPI development is to identify indicators that are quantitative, that can be measured objectively, and that are relevant to the rehabilitation process. Therefore, within each of the Key Components of landform rehabilitation that were identified, it was necessary to break that component of the rehabilitation process into elements, tasks, and finally, into quantitative, measurable parameters (Table 2).

For example, for the Key element of Landform design and Specific task of "Stability of design demonstrated" (Table 2), the quantifiable action required is

"WEPP simulations using site parameters, with predicted erosion $<12$ t/haly at all points on slopes with practicable levels of tree trash or rock cover. Vegetation not considered."

Implicit in that requirement for erosion modelling is the use of a climate file representative of the site. The decision not to consider effects of vegetation on erosion is based on assessments of vegetation in the area showing that, in areas of such low rainfall, the levels of contact cover produced by vegetation are low, and may not impact significantly on slope stability. 
Table 2 Key elements and specific tasks associated with the planning component

\begin{tabular}{|c|c|}
\hline Key elements & Specific tasks \\
\hline \multirow{3}{*}{$\begin{array}{l}\text { Definition of goals for the } \\
\text { rehabilitated landform }\end{array}$} & Specific end land use has been defined \\
\hline & Acceptable levels of off-site impacts have been defined \\
\hline & Stakeholder consultation has been undertaken and agreement achieved \\
\hline \multirow{4}{*}{$\begin{array}{l}\text { Characterization of soils and } \\
\text { spoils }\end{array}$} & Acid mine drainage potential determined \\
\hline & Contaminants identified (if any) \\
\hline & $\begin{array}{l}\text { Stability of material determined in regards to dispersiveness, salinity } \\
\text { and potential for erosion }\end{array}$ \\
\hline & Erodibility risks identified \\
\hline \multirow[t]{4}{*}{ Preparation of landform design } & Stability of design demonstrated \\
\hline & Water run-on and off is appropriately managed \\
\hline & Design is consistent with the identified end land use \\
\hline & $\begin{array}{l}\text { All identified risk factors have been managed (e.g. acid-producing } \\
\text { material, contaminants and/or off-site impacts) }\end{array}$ \\
\hline \multirow{5}{*}{$\begin{array}{l}\text { Identification of plant species } \\
\text { required }\end{array}$} & Permanent monitoring transects in analogue communities are established \\
\hline & Monitoring program design determined \\
\hline & Completion criteria for vegetation communities are set. \\
\hline & Species requirements to meet completion criteria have been compiled \\
\hline & Plant density requirements are determined \\
\hline $\begin{array}{l}\text { Determine soil fertility needs and } \\
\text { amendments }\end{array}$ & $\begin{array}{l}\text { Soil analysis for } \mathrm{pH}, \mathrm{EC} \text {, cations and cation exchange capacity, available } \\
\mathrm{P} \text { and trace elements in topsoil and underlying spoil is conducted }\end{array}$ \\
\hline
\end{tabular}

It is possible to compare the five Key Components of rehabilitation recognised by the KPI process and associated suggested levels of bond return with those currently recommended (Table 3 ). It can be seen that current guidelines do not consider planning, and give considerable weight to primary earthworks, whereas the MMO approach gives greater emphasis to the successful completion of rehabilitation earthworks to a specified standard provided planning has also been a part of the rehabilitation process. 
Table 3 Comparison of DoIR Bond Reduction Policy with that Proposed by MMO

\begin{tabular}{|c|c|c|c|c|c|}
\hline $\begin{array}{l}\text { DoIR } \\
\text { Stage }\end{array}$ & Action & $\begin{array}{l}\text { DoIR } \\
\text { Suggested } \\
\text { bond } \\
\text { level }^{\mathrm{A}}\end{array}$ & $\begin{array}{l}\text { Suggested } \\
\text { Stage }\end{array}$ & Action & $\begin{array}{l}\text { Suggested } \\
\text { bond level if } \\
\text { KPIs are } \\
\text { met }^{\mathrm{A}}\end{array}$ \\
\hline & & & 1 & Planning & \\
\hline 1 & $\begin{array}{l}\text { Primary } \\
\text { Earthworks }\end{array}$ & $\$ 5000$ & \multirow[t]{2}{*}{2} & \multirow[t]{2}{*}{$\begin{array}{l}\text { Landform } \\
\text { construction }\end{array}$} & \multirow[t]{2}{*}{$\$ 2000$} \\
\hline 2 & $\begin{array}{l}\text { Finishing } \\
\text { Earthworks }\end{array}$ & $\$ 3000$ & & & \\
\hline \multirow[t]{2}{*}{3} & \multirow[t]{2}{*}{ Revegetation } & \multirow[t]{2}{*}{$\$ 2000$} & 3 & $\begin{array}{l}\text { Initial Monitored } \\
\text { Performance }\end{array}$ & $\$ 1000$ \\
\hline & & & 4 & $\begin{array}{l}\text { Monitored } \\
\text { Performance }\end{array}$ & \\
\hline 4 & Relinquishment & $\$ 0$ & 5 & $\begin{array}{l}\text { Sustainability } \\
\text { (Relinquishment) }\end{array}$ & $\$ 0$ \\
\hline
\end{tabular}

A: bond rate in $\$$ per ha if completion criteria are met.

\subsection{Potential Impacts of the KPI Process}

Adoption of KPIs is expected to have a range of impacts, including improved management of the rehabilitation process and a focus on record-keeping and continuous improvement, as well as its primary role of providing information on rehabilitation progress and success.

\subsubsection{Likely impacts on management of landform rehabilitation activities}

The KPI process is becoming a valuable management technique for MMO. It establishes a comprehensive, soundly-based set of procedures by which landform planning, design, construction and rehabilitation must proceed.

Its requirement for sign-off on the construction of rehabilitated landforms to specification has obvious potential to achieve quality assurance for landform construction. Importantly, feedback on whether or not a landform has met design specifications will be received rapidly, rather than some years later once erosion may be firmly established. Rapid feedback can not only assist in the training of site staff, but can also enable remedial actions to be carried out promptly before damage to batter slopes becomes severe. Effectively, erosive failure is no longer the main mechanism used to assess the quality of landform construction.

There are also benefits from the design process, in that priorities for landform construction are more clearly defined. For example, discharges of runoff from the top of dumps onto batter slopes have been observed (and modelled) as being major causes of erosion. Consequently, MMO ensures that landforms have compacted perimeter bunds together with a number of cross-bunds and surface ripping to control concentration of water on the tops of the landforms. Similarly, the degree of flow concentration that occurs on batter slopes has been shown by computer simulations to dramatically affect predicted erosion rates. In response, the magnitude of surface rip lines has been greatly reduced to minimise the potential for cross-slope accumulation of flow in the rip lines. Equally, the importance of stockpiling both laterite and tree debris for use in stabilising outer batter slopes is now clearly recognised, and it is possible to estimate likely quantities required, well in advance of landform construction.

\subsubsection{Record keeping and continuous improvement}

For many sites, information on the design, construction, and revegetation of existing landforms can be extremely scanty, due to a combination of minimal recording of information and loss of records due to staff turnover. This can make it extremely difficult to assess why particular areas of rehabilitation may have 
succeeded or failed, and virtually impossible to recommend remedial actions. Under such conditions, it is extremely difficult for a site to develop "proven" rehabilitation techniques, as there is no opportunity to learn from mistakes or successes.

However, for MMO, the characterisation and design components of the KPI process automatically provide documentation of landform design and construction, including detailed information on material properties, and recommendations for fertiliser and amendment applications. Following completion of rehabilitation works, monitoring will provide information on erosion (interpreted on the basis of annual rain and variations therein), on vegetation establishment and growth, and on other features of the landform's development. MMO is now developing a spatial database to store monitoring information, so that site staff can easily access and track KPI progress for each rehabilitated landform and parts thereof.

Feedback on the progress of the various slopes is essential for refinement of computer modelling of runoff and erosion, as improved precision and confidence in simulations can lead to less conservative and more cost-effective designs. Equally, information on vegetation performance and responses to fertilisers and amendments will be valuable, as existing information on fertiliser responses tends to concentrate on agricultural plant species, generally under higher rainfall.

\section{CONCLUSIONS}

The development and negotiation of KPIs for rehabilitation success has created a process that gives certainty and objectivity to the assessment of rehabilitation success at MMO. It provides an agreed basis for return of Environmental Performance Bonds, which is an essential economic incentive for progressive rehabilitation on any minesite.

Recent experience indicates that the KPIs developed by MMO, due to their logical basis and emphasis on good practice, are now beginning to be reflected in changes to industry guidelines.

For example, material characterization is a major component of the KPI planning component. It is notable that recent DoIR guidelines (DoIR, 2006) now specify for the first time a range of analyses that should be made to characterize topsoils and wastes excavated by mining. Although not as comprehensive as those considered in the KPIs developed for MMO, they represent a considerable step forward. The guidelines may yet need refinement in their treatment of exchangeable cations and dispersion potential of saline soils, and there is no requirement for assessment of erodibility.

Similarly, the processes adopted and the KPIs selected and put in place by MMO are compliant with the recently released guidance statement from the Environmental Protection Authority of Western Australia (EPA) on the assessment of rehabilitated terrestrial ecosystems (EPA, 2006). Within the KPIs, plant fecundity and soil seed bank measures assess whether the system is becoming self-sustaining and resilient, and there are species diversity, abundance and cover targets. The requirement for species in rehabilitated communities to be local and that dominant species from reference communities should also be dominant in the rehabilitated area aims to identify that canopy and keystone species are returned as required by EPA (2006).

The value of the KPI process lies not only in its documentation of rehabilitation progress for reporting to regulatory agencies, but also in its strong impact on minesite practice, and potential to be a major factor in rehabilitation success. The ability to achieve bond release is important, but it is also essential that risk of failure of minesite rehabilitation works be minimised, and that the procedures enable and encourage continued improvement in rehabilitation practices. 


\section{REFERENCES}

Department of Mines and Energy (1996) Guidelines for Mining in Arid Areas Western Australian Government, Perth.

Department of Industry and Resources (2003) Environmental Branch Bond Guideline, Western Australian Government, Perth.

Department of Industry and Resources (2006) Guidelines for mining proposals in Western Australia, February 2006, Western Australian Government, Perth.

Environmental Protection Agency (2006) Guidance for the Assessment of Environmental Factors, No 6. Rehabilitation of terrestrial ecosystems, Western Australian Government, Perth. 